\title{
Astrocytes As the Main Players in Primary Degenerative Disorders of the Human Central Nervous System
}

\author{
Francisco Capani ${ }^{1,2 *}$, Cecilia Quarracino ${ }^{1}$, Roberto Caccuri1 and Roberto E. P. Sica ${ }^{1}$ \\ ${ }^{1}$ Instituto de Investigaciones Cardiologicas ININCA UBA CONICET, Buenos Aires, Argentina, ${ }^{2}$ Instituto de Ciencias \\ Biomédicas, Facultad de Ciencias de la Salud, Universidad Autónoma de Chile, Temuco, Chile
}

Along the last years it has been demonstrated that non-neural cells play a major role in the pathogenesis of the primary degenerative disorders (PDDs) of the human central nervous system. Among them, astrocytes coordinate and participate in many different and complex metabolic processes, in close interaction with neurons. Moreover, increasing experimental evidence hints an early astrocytic dysfunction in these diseases. In this mini review we summarize the astrocytic behavior in PDDs, with special consideration to the experimental observations where astrocytic pathology precedes the development of neuronal dysfunction. We also suggest a different approach that could be consider in human investigations in Alzheimer's and Parkinson's disease. We believe that the study of PDDs with human brain samples may hold the key of a paradigmatic physiopathological process in which astrocytes might be the main players.

OPEN ACCESS

Edited by:

George E. Barreto,

Pontificia Universidad Javeriana,

Colombia

Reviewed by:

Anna Maria Colangelo,

University of Milano-Bicocca, Italy

Christiane Charriaut-Marlangue,

Institut National de la Santé et de la

Recherche Médicale, France

*Correspondence:

Francisco Capani

franciscocapani@hotmail.com

Received: 02 December 2015 Accepted: 23 December 2015

Published: 04 February 2016

Citation:

Capani F, Quarracino C, Caccuri R and Sica REP (2016)

Astrocytes As the Main Players

in Primary Degenerative Disorders

of the Human Central Nervous

System. Front. Aging Neurosci. 8:45.

doi: 10.3389/fnagi.2016.00045
Keywords: astrocytes, primary degenerative disorders, human central nervous system, neurodegeneration, primary astrocytic degeneration

\section{FIRST STEPS: NEURODEGENERATION}

Since the beginning of the 20th century relentlessly progressive neurological diseases have classically been attributed to a primary neuronal dysfunction. This affirmation applies to Parkinson disease (PD), Alzheimer disease (AD), amyotrophic lateral sclerosis (ALS) and frontotemporal dementia (FTD), among others (Pendlebury et al., 1987; Manetto et al., 1988). Therefore, most investigations have been carried out under this belief, leading to the coining of the term "neurodegeneration." This paradigm was later on applied to psychiatric diseases such as Schizophrenia and Major depression (Harrison, 1999; Delgado, 2004). As a result of those efforts, a detailed description of neurons' characteristics in the main affected areas in those diseases as well as a broadening of the knowledge of neuronal functioning was achieved. Since then, several physiopathological hypotheses were constructed; notwithstanding that when put into practice by therapeutical testing, results have not met the expectations (McDermott and Rowland, 2001; Broadstock et al., 2014).

In the 90s, a new era began that considered the possibility of a more important role of the so far neglected neuroglia. This led to different findings opposed to the belief of the astrocytes sole function being neuronal structural support.

Astrocytes have been found to have a much more active role that the one predicted by the earlier guessers. Particularly, they are involved in the ions exchange with neurons, they are organized as a syncytium that allows them to interchange information with other astrocytes residing in a defined net through different types of $\mathrm{Ca}^{+++}$signals while regulating the release of signaling molecules 
involved in the production of trophic factors, transmitters and transporters that when released to the extracellular medium will modulate the synaptic activity synchronizing the neuronal functions. Also they are involved in the extracellular $\mathrm{K}^{+}$uptake, in synaptogenesis and gene expression; adapting, at the same time, the permeability of the blood-brain barrier to the neuronal and synaptic needs (Reichenbach et al., 2010; Gordon et al., 2011; Rash et al., 2012; Khakh and Sofroniew, 2015). A more exhaustive description of the astrocytes properties and functions is beyond the scope of this mini review and is detailed elsewhere (Sica, 2015).

\section{THE NEW ERA: PRIMARY DEGENERATIVE DISORDERS}

Slowly but relentlessly, the results of several studies confirmed the existence of an active role played not only by the astrocytes but also by microglia. Mounting evidence suggests that astrocytes modulate microglial response, through the establishment of a complex cross-talk between both types of cells mediated by the production of different chemokines and cytokines (Cudaback et al., 2015; Rothhammer and Quintana, 2015). Therefore, we think that the broader term primary degenerative disorders of the central nervous system (PDD CNS) alludes to the complex pathology of these diseases (in contrast to the classic term neurodegeneration) and will be used henceforward in this article.

Astrocytic findings in the PDDs include:

In FTD, the classic approach subdivided the frontotemporal anatomic atrophy with regards to the concomitant histopathological findings, that is: Pick disease when tau-positive intraneuronal inclusions were found, FTD with motor neuron disease when tau-negative-ubiquitine-positive intracellular inclusions were present in motor neurons or Frontotemporal Lobar Degeneration when no particular histopathological features were observed (Broe et al., 2004). On the contrary, recent studies have demonstrated that regardless of the presence or absence of the "classic" neuronal inclusions, clinical disease progression is associated with the extent of neuronal loss, the degree of extracellular microvacuolation and, regarding glial pathology, the level of both astrogliosis and astrocytic apoptosis (Broe et al., 2004; Kersaitis et al., 2004).

With regards to $\mathrm{PD}$, microgliosis has been found in a sustained fashion by different authors associated with the creation and maintenance of a vigorous inflammatory state at the substantia nigra pars compacta (McGeer and McGeer, 2008; McGann et al., 2012) and striatum, the latter of a strikingly similar characteristics in animal models and human brain samples (Charron et al., 2014). The mentioned state seems to be modulated by astrocytes, through the exocytosis of paracrine factors in the substantia nigra such as ICAM-1 and IL-6, which in turn act as stimulators of microglia migration (McGeer and McGeer, 2008).

Regarding $\mathrm{AD}$, in a triple transgenic mouse model it has been shown that the presence of senile plaques in the hippocampus induces a mild astrocytic (and microglial) reaction within the A $\beta$ plaques' periphery (Olabarria et al., 2010); a finding that was not observed in the entorhinal or prefrontal cortex (Yeh et al., 2011; Kulijewicz-Nawrot et al., 2012). However, in human brain samples astroglial reaction, although present and with a clear hippocampal preference, seems to be less clearly associated with amyloid deposition at least in the lateral temporal cortex (Wharton et al., 2009; Olabarria et al., 2010; Simpson et al., 2010; Verkhratsky et al., 2010, 2014a; Yeh et al., 2011; Prokop et al., 2013).

Both in Major Depression and Schizophrenia there seems to be a mild astrocytic atrophy (characterized mainly by a decreased expression of GFAP) without a definitive consensus in relation to the stability of the total number of astrocytes (Verkhratsky et al., 2014b; Verkhratsky and Parpura, 2015). Moreover, in Schizoprhenia, several functional astrocytic changes have been described such as a diminished expression of EAAT1 and EAAT1 (human glutamate transporters) in the prefrontal cortex, augmented synthesis of condroitin sulfate proteoglycans in the amygdala and entorhinal cortex, altered metabolism of D-serine, elevated levels of kynurenic acid (NMDA inhibitor synthesized by astrocytes), etc. (Rajkowska and Miguel-Hidalgo, 2007; Alexander et al., 2012; Feresten et al., 2013; Verkhratsky et al., 2014b; Verkhratsky and Parpura, 2015).

Finally, in ALS, astrogliosis both in white and gray matter is a very important hallmark of the illness all along its course (Yamanaka et al., 2008; Lasiene and Yamanaka, 2011; Sica, 2012). In the SOD ${ }^{\mathrm{G} 93 \mathrm{~A}}$ transgenic mouse model astroglial atrophy has been described restricted to the astrocytes associated with the affected motor neurons (Rossi et al., 2008). Microglia activation is also increased in ALS and in another SOD1 mouse model Yamanaka et al. (2008) demonstrated that it could be modulated by the manipulation of astrocytic behavior (Yamanaka et al., 2008; Lasiene and Yamanaka, 2011; Sica, 2012).

\section{Special Consideration}

A particular difficulty in the study of these diseases is that they mostly represent a deterioration of a highly evolved cognitive and/or motor functioning system. Therefore, and punctually in psychiatric illnesses, it seems that animal models are far from resembling all the peculiarities of the human diseases, even if the anatomopathological findings can be mimicked. On the other hand, human testing is ethically inappropriate for obvious reasons and therefore, the most representative research tool available is the study of post mortem human brains (Harrison, 1999; Broadstock et al., 2014). Furthermore, since clinical diagnosis relies in a constellation of signs and symptoms that are secondary to a physiopathogenic process that is far from recently starting, the study of the disease early-stages is extremely difficult. All the above determines hazards to the methodological study approach of many hypotheses, particularly those involving disease onset and progression.

\section{TEMPORALITY CLUES}

We reviewed the international literature in order to find descriptions in human or animal models which may support the hypothesis that astrocyte pathology precedes neuronal damage (Table 1). 
TABLE 1 | Experimental findings suggestive of primary astrocytic damage.

\begin{tabular}{|c|c|c|c|}
\hline Disease & Reference & Species & Findings \\
\hline \multirow[t]{2}{*}{ FTD } & Broe et al., 2004 & Human & $\begin{array}{l}\text { Astrocytic apoptosis is present at early stages and increases } \\
\text { with disease progression. }\end{array}$ \\
\hline & Kersaitis et al., 2004 & Human & Astrogliosis is present at early stages of the disease. \\
\hline PD & Halliday and Stevens, 2011 & Mice & $\begin{array}{l}\text { Astrocytic cytoplasmatic } \alpha \text {-synuclein deposition precedes } \\
\text { neuronal damage. }\end{array}$ \\
\hline \multirow[t]{3}{*}{$A D$} & Olabarria et al., 2010 & Mice $(3 x \operatorname{Tg})$ & $\begin{array}{l}\text { Hippocampal astroglia atrophy (6th month) precedes the } \\
\text { extracellular } A \beta \text { deposition (12th month). }\end{array}$ \\
\hline & Yeh et al., 2011 & Mice $(3 \times T g)$ & $\begin{array}{l}\text { Entorhinal astroglial atrophy (1st month) precedes } \\
\text { neurodegeneration ( } 12 \text { months of age). }\end{array}$ \\
\hline & Kulijewicz-Nawrot et al., 2012 & Mice $(3 x \operatorname{Tg})$ & $\begin{array}{l}\text { Medial prefrontal astroglial atrophy ( } 1 \text { month of age) precedes } \\
\text { neurodegeneration ( } 12 \text { months of age). }\end{array}$ \\
\hline \multirow[t]{2}{*}{ AND } & Rama Rao and Norenberg, 2014 & Mice & Hepatic encephalopathy: selective astrocyte swelling. \\
\hline & Hazell, 2009 & Human Rats & $\begin{array}{l}\text { Wernicke's encephalopathy: loss of EAAT1 and EAAT2 } \\
\text { astrocytic glutamate transporters. }\end{array}$ \\
\hline \multirow[t]{4}{*}{ ALS } & Bruijn et al., 1997 & Mice (SOD1 ${ }^{G 85 R}$ ) & $\begin{array}{l}\text { SOD1 astrocyte inclusions precede similar neuronal inclusions } \\
\text { and later clinical signs. }\end{array}$ \\
\hline & Rossi et al., 2008 & Mice (SOD1 G93A) & $\begin{array}{l}\text { Abnormal spheroid-shaped astrocytes ( } 75 \text { th day) in the ventral } \\
\text { horns of the lumbar spinal cord, astrogliosis of the ventral and } \\
\text { dorsal horns before clinical sings and evident neuron number } \\
\text { reduction (100th day). }\end{array}$ \\
\hline & Papadeas et al., 2011 & Rats (SOD1 $\left.{ }^{\mathrm{G} 93 \mathrm{~A}}\right)$ & Selective astrocytic mutation of SOD $1^{\mathrm{G} 93 \mathrm{~A}}$ leads to ALS signs. \\
\hline & Tong et al., 2013 & Rats & $\begin{array}{l}\text { Selective astrocytic mutation of Tar DNA-binding protein } 43 \\
\text { (TDP-43) leads to ALS signs. }\end{array}$ \\
\hline SCA & Custer et al., 2006 & Mice & Bergman glia expressing ataxin-7 lead to SCA symptoms. \\
\hline \multirow[t]{2}{*}{ HD } & Faideau et al., 2010 & Mice Human & $\begin{array}{l}\text { Selective expression of mutant Huntingtin in mice astrocytes } \\
\text { leads to HD signs. } \\
\text { Astrogliosis in the dorsal stratum in two human brain samples } \\
\text { without clinical symptoms (grade 0). }\end{array}$ \\
\hline & Bradford et al., 2009 & Mice & $\begin{array}{l}\text { Selective expression of mutant Huntingtin in mice astrocytes } \\
\text { leads to HD signs. }\end{array}$ \\
\hline
\end{tabular}

FTD, Frontotemporal dementia; PD, Parkinson disease; AD, Alzheimer's disease; AND, Acquired neuropsychiatric disease; ALS, Amyotrophic lateral sclerosis; SCA, Spinocerebellar ataxia; $H D$, Huntington disease.

Human anatomical material is scarce regarding this point because cadaveric material, such as brains and spinal cords, belongs mostly to patients who at the time of their death were already at late stages of their pathological process.

However, there are some observations in animal experimentation, which situates astrocytic damage at the beginning of the pathological timeline. Examples are as follows:

\section{Frontotemporal Dementia}

In recent human studies astrocytes showing apoptotic signs were frequently found at the beginning of the disease when neuronal loss was yet very rare (Broe et al., 2004). Moreover, in a different study which focused on histological characteristics, astrogliosis was found to be present at early stages of the disease (Kersaitis et al., 2004). In later-stage cases, astrocytic apoptosis markers increased while astrogliosis was found with less frequency (Broe et al., 2004; Kersaitis et al., 2004). These findings support the notion that glial pathology occurs at the very starting of the illness besides being a major feature during the course of the disease.

\section{Parkinson Disease}

In an extensive research done in human brains, Braak et al. (2003) demonstrated that $\alpha$-synuclein deposition involves a wider brain area than the one that becomes symptomatic and that these symptoms appear at a later stage on the course of the disease, once neurons become affected at a high percentage. Curiously, the cells that do develop changes at early stages of intracellular $\alpha$-synuclein deposition are astrocytes. In animal models, the accumulation of astrocytic cytoplasmatic $\alpha$-synuclein eventually leads not only to astrocytic dysfunction but also to microglia activation through the release of cytokines and chemokines. These changes, in turn, determine the injury and eventually the non-cell autonomous killing of neurons (Halliday and Stevens, 2011).

In addition, several of the proteins codified by the altered genes in autosomic recessive forms of hereditary PD (Parkin, PINK-1, DJ-1), are mainly concentrated in astrocytes (McGeer and McGeer, 2008; Halliday and Stevens, 2011).

\section{Alzheimer Disease}

In one of the only two transgenic animal models that mimic both the plaque deposition and the neurofibrillary tangles observed in humans (Oddo et al., 2003) it has been observed that the early-term and start of the mid-term stages of the illness are characterized by the presence of hippocampal astroglia atrophy (6 months of age). This period is followed by the appearance 
of $\mathrm{A} \beta$ plaques and neurodegeneration in association with the persistence of astrocyte atrophy as well as astrogliosis in the periplaque area (Olabarria et al., 2010). Moreover, in the same mouse model early astrocytic atrophy was also found in the entorhinal cortex at 1 month of age (Yeh et al., 2011) and in the prefrontal dorsolateral cortex since the $3 \mathrm{rd}$ month of age (Kulijewicz-Nawrot et al., 2012), in both cases without later periplaque astrogliosis and preceding neuronal dysfunction by even broader lapses.

\section{Acquired Neuropsychiatric Diseases}

In several acquired neuropsychiatric disorders such as hepatic encephalopathy, Wernicke encephalopathy and heavy metals encephalopathy astrocytes are the primary affected cells (Rönnbäck and Hansson, 1992; Hazell, 2009; Rama Rao and Norenberg, 2014). Their dysfunction is believed to determine neuronal injury and eventually death through glutamate toxicity. Astrocytes are the only brain cells capable of metabolizing ammonia through the enzyme glutamine synthetase. However, the excessive concentration of ammonia in hepatic encephalopathy determines an uncommon availability of glutamate precursors as well as an increased production of reactive oxygen and nitrogen species which ultimately lead to astrocytic mitochondrial dysfunction (Rama Rao and Norenberg, 2014).

\section{Amyotrophic Lateral Sclerosis}

Several observations support the idea that there is an early if not primary astrocytic damage in this disease (Sica, 2012).

To begin with, it was observed that transplantation of mutated SOD 1 expressing glial progenitors, able to differentiate into astrocytes, into the spinal cord of wild type rats induce motor neurons degeneration and clinical symptoms in vivo (Papadeas et al., 2011; Tong et al., 2013).

Furthermore, Rossi et al. (2008) employing the transgenic mouse model expressing the human SOD $1^{\mathrm{G} 93 \mathrm{~A}}$, identified a degenerative process involving a subset of astrocytes confined to the microenvironment of the spinal motor neurons. More importantly, the time-course of appearance of these cells was at the 75th day of age, that is, before the loss of motor cells. Moreover, the quoted astrocyte degeneration and its consequences were experimentally slowed down by the injection of 2-methyl-6-pyridine, a selective antagonist to the mGluR5 glutamate receptor. Therefore, glutamate toxicity seems to have a major role in astrocyte and neuron degeneration in mutant SOD1 ${ }^{\mathrm{G} 93 \mathrm{~A}}$ mice. These findings are consistent with the previously reported selective up-regulation of mGluR5 in astrocytes in the ventral spinal cord of ALS patients (Aronica et al., 2001).

Other notorious publication that has been referred to ever since is Bruijn et al. (1997) description of findings in genetically induced ALS mice. In this experimental study, transgenic and control mice were sacrificed at different ages and their CNS analyzed. They noted that the first pathological findings were astrocytic cytoplasmic aggregates that were approximately 1 month later observed in neurons and which preceded the clinical disease onset by 2.5 months.

\section{Spinocerebellar Ataxia (SCA)}

Custer et al. (2006) demonstrated that in the polyglutamine disease SCA7, Purkinje cells undergo non-cell-autonomous degeneration in transgenic animals. They generated mice expressing ataxin-7 only in Bergmann glia (a specialized type of cerebellum's astrocytes in close contact with Purkinje cells), which was sufficient to produce ataxia and neurodegeneration. In a similar fashion, Garden et al. (2002) also demonstrated that transgenic mice expressing ataxin7 with 92 glutamines repeats (92Q) in non-neural cells at the cerebellum promoted Purkinje cells' degeneration and therefore developed a dramatic neurological phenotype presenting as a gait ataxia and culminating in premature death despite the absence of its expression in Purkinje cells.

\section{Huntington's Disease (HD)}

In animal mouse models it was observed that mice expressing mutated Huntingtin (mhtt) in neurons show mild or no neurological sings, while mice expressing mhtt only in astrocytes have a reduced expression of astrocyte glutamate transporters and end up developing neurological deficits and an earlier neuronal death than when compared with control transgenic or wild-type mice (Gu et al., 2005; Bradford et al., 2009).

These observations are also supported by cultures results, where co-culturing wild mice neurons with astrocytes that overexpress mhtt have shown that neurons undergo apoptosis, once more suggesting that those astrocytes have a deleterious effect onto normal neurons (Shin et al., 2005).

In humans, Faideau et al. (2010) observed reactive astrocytosis in the dorsal striatum in grade $0 \mathrm{HD}$ subjects, when no neuronal damage is still apparent, with dorso-ventral striatum progression through grade 4 specimens. Despite being only two 0 HD human brain samples, we believe that these findings deserve at least further investigation.

\section{CONCLUSION}

It has broadly been observed an early astrocytic dysfunction in the PDDs of the CNS. In the present mini review, this concept has been exemplified in CNS at its whole length: starting in the spine or the brain stem in ALS patients, ascending to the midbrain in $\mathrm{PD}$, the cerebellum in SCA-7, the striatum in $\mathrm{HD}$, the hippocampus in $\mathrm{AD}$, the prefrontal cortex in FTD and, finally, compromising in a more subtle fashion the whole cortical gray matter in SCZ.

We advocate that these observations obtained from different degenerative pathologies, but mostly from experimental animal studies, may be the trees from a forest characterized by primary astrocytic dysfunction as the main process starting them.

We believe that in these particular pathologies, investigations conducted on human brain samples are absolutely necessary to confirm and expand the findings achieved in animal studies. This is based on the fact that particularly in cognitive pathology, anatomopathological findings do not necessary correlate with 
clinical symptoms (hence the actual disease) and that healthy animals do not acquire the high mental functions later to be lost, and therefore their analysis does not necessarily represent the human reality.

As a non yet explored approach, were astrocytic dysfunction to be of a diffuse fashion, the classically end-stage affected brain areas could be the ones to harbor early astrocytic pathology without neuron disease. Were astrocytic pathology to be restricted to a focused cerebral region, early changes in already symptomatic patients are unlikely to be studied although Parkinson and Alzheimer's disease may be the exceptions due to their known sequence of progression.

\section{REFERENCES}

Alexander, K. S., Wu, H. Q., and Bruno, J. P. (2012). Acute elevations of brain kynurenic acid impair cognitive flexibility: normalization by the alpha7 positive modulator galantamine. Psychopharmac 220, 627-637. doi: 10.1007/s00213011-2539-2

Aronica, E., Catania, M. V., Geurts, J., Yankaya, B., and Troost, D. (2001). Immunohistochemical localization of group I and II metabotropic glutamate receptors in control and amyotrophic lateral sclerosis human spinal cord: upregulation in reactive astrocytes. Neuroscience 105, 509-520. doi: 10.1016/S0306-4522(01)00181-6

Braak, H., Del Tredici, K., Rüb, U., de Vos, R. A., Jansen Steur, E. N., and Braak, E. (2003). Staging of brain pathology related to sporadic Parkinson's disease. Neurobiol. Aging 24, 197-211. doi: 10.1016/S0197-4580(02)00065-9

Bradford, J., Shin, J. Y., Roberts, M., Wang, C. E., Li, X. J., and Li, S. (2009). Expression of mutant huntingtin in mouse brain astrocytes causes agedependent neurological symptoms. Proc. Natl. Acad. Sci. U.S.A. 106, 2248022485. doi: 10.1073/pnas.0911503106

Broadstock, M., Ballard, C., and Corbett, A. (2014). Latest treatment options for Alzheimer's disease, Parkinson's disease dementia and dementia with Lewy bodies. Expert Opin. Pharmacother. 15, 1797-1810. doi: 10.1517/14656566.2014.936848

Broe, M., Kril, J., and Hallidal, G. M. (2004). Astrocytic degeneration relates to the severity of disease in frontotemporal dementia. Brain 127, 2214-2220. doi: 10.1093/brain/awh250

Bruijn, L. I., Becher, M. W., Lee, M. K., Anderson, K. L., Jenkins, N. A., Copeland, N. G., et al. (1997). ALS-linked SOD1 mutant G85R mediates damage to astrocytes and promotes rapidly progressive disease with SOD1containing inclusions. Neuron 18, 327-338. doi: 10.1016/S0896-6273(00) 80272-X

Charron, G., Doudnikoff, E., Canron, M. H., Li, Q., Véga, C., Marais, S., et al. (2014). Astrocytosis in parkinsonism: considering tripartite striatal synapses in physiopathology? Front. Aging Neurosci. 6:258. doi: 10.3389/fnagi.2014. 00258

Cudaback, E., Yang, Y., Montine, T. J., and Keene, C. D. (2015). APOE genotypedependent modulation of astrocyte chemokine CCL3 production. Glia 63, 51-65. doi: 10.1002/glia.22732

Custer, S. K., Garden, G. A., Gill, N., Rueb, U., Libby, R. T., Schultz, C., et al. (2006). Bergmann glia expression of polyglutamine-expanded ataxin-7 produces neurodegeneration by impairing glutamate transport. Nat. Neurosci. 9, 1302-1311. doi: 10.1038/nn1750

Delgado, P. L. (2004). Common pathways of depression and pain. J. Clin. Psychiatry 65(Suppl. 12), 16-19. doi: 10.1016/j.jad.2014.03.051

Faideau, M., Kim, J., Cormier, K., Gilmore, R., Welch, M., Auregan, G., et al. (2010). In vivo expression of polyglutamine-expanded huntingtin by mouse striatal astrocytes impairs glutamate transport: a correlation with Huntington's disease subjects. Hum. Mol. Genet. 19, 3053-3067. doi: 10.1093/hmg/ddq212

Feresten, A. H., Barakauskas, V., Ypsilanti, A., Barr, A. M., and Beasley, C. L. (2013). Increased expression of glial fibrillary acidic protein in prefrontal cortex in psychotic illness. Schizophr. Res. 150, 252-257. doi: 10.1016/j.schres.2013.07.024
We support the idea that a study with human samples focused in the context of the different diseases so far mentioned might allow to ascertain through detailed description characteristics previously overlooked, thus obtaining hints of a paradigmatic physiopathological process in which the astrocytes might be the main players.

\section{AUTHOR CONTRIBUTIONS}

All the listed authors have agreed on all of the contents and have contributed equally to its production.

Garden, G. A., Libby, R. T., Fu, Y. H., Kinoshita, Y., Huang, J., Possin, D. E., et al. (2002). Polyglutamine-expanded ataxin-7 promotes non-cellautonomous purkinje cell degeneration and displays proteolytic cleavage in ataxic transgenic mice. J. Neurosci. 22, 4897-4905. doi: 10.1016/j.neuron.2011. 05.027

Gordon, G. R., Howarth, C., and Mac Vicar, V. A. (2011). Bidirectional control of arteriole diameter by astrocytes. Exp. Physiol. 96, 393-399. doi: 10.1113/expphysiol.2010.053132

Gu, X., Li, C., Wei, W., Lo, V., Iwasato, T., Itohara, S., et al. (2005). Pathological cell-cell interactions elicited by a neuropathogenic form of mutant Huntingtin contribute to cortical pathogenesis in HD mice. Neuron 46, 433-444. doi: 10.1016/j.neuron.2005.03.025

Halliday, G. M., and Stevens, C. H. (2011). Glia: initiators and progressors of pathology in Parkinson's disease. Mov. Disord. 26, 6-17. doi: 10.1016/S01974580(02)00065-9

Harrison, P. J. (1999). The neuropathology of schizophrenia. A critical review of the data and their interpretation. Brain 122, 593-624. doi: 10.1093/brain/122.4.593

Hazell, A. S. (2009). Astrocytes are a major target in thiamine deficiency and Wernicke's encephalopathy. Neurochem. Int. 55, 129-135. doi: 10.1007/s11064012-0955-2

Kersaitis, C., Halliday, G. M., and Kril, J. J. (2004). Regional and cellular pathology in frontotemporal dementia: relationship to stage of disease in cases with and without Pick bodies. Acta Neuropathol. 108, 515-523. doi: 10.1007/S00401-0040917-0

Khakh, B. S., and Sofroniew, M. V. (2015). Diversity of astrocyte functions phenotypes in neural circuits. Nat. Neurosci. 18, 942-952. doi: 10.1038/nn.4043

Kulijewicz-Nawrot, M., Verkhratsky, A., Chvátal, A., Syková, E., and Rodríguez, J. J. (2012). Astrocytic cytoskeletal atrophy in the medial prefrontal cortex of a triple transgenic mouse model of Alzheimer's disease. J. Anat. 221, 252-262. doi: $10.1111 / j .1469-7580.2012 .01536 . x$

Lasiene, J., and Yamanaka, K. (2011). Glial cells in amyotrophic lateral sclerosis. Neurol. Res. Int. 2011, 718987. doi: 10.1155/2011/718987

Manetto, V., Perry, G., Tabaton, M., Mulvihill, P., Fried, V. A., Smith, H. T., et al. (1988). Ubiquitin is associated with abnormal cytoplasmic filaments characteristic of neurodegenerative diseases. Proc. Natl. Acad. Sci. U.S.A. 85, 4501-4505. doi: 10.1073/pnas.85.12.4501

McDermott, M. P., and Rowland, L. P. (2001). ALS defeats gabapentin: reflections on another failed treatment. Neurology 56, 826-827. doi: 10.1212/WNL.56.7.826

McGann, J. C., Lioy, D. T., and Nabdel, G. (2012). Astrocytes conspire with neurons during progression of neurological diseases. Curr. Opin. Neurobiol. 22, 550-558. doi: 10.1016/j.conb.2012.03.009

McGeer, P. L., and McGeer, E. G. (2008). Glial reactions in Parkinson's disease. Mov. Disord. 23, 474-483. doi: 10.1002/mds.21751

Oddo, S., Caccamo, A., Kitazawa, M., Tseng, B. P., and LaFerla, F. M. (2003). Amyloid deposition precedes tangle formation in a triple transgenic model of Alzheimer's disease. Neurobiol. Aging 24, 1063-1070. doi: 10.1016/S08966273(03)00434-3

Olabarria, M., Noristani, H. N., Verkhratsky, A., and Rodriguez, J. J. (2010). Concomitant astroglial atrophy and astrogliosis in a triple transgenic animal model of Alzheimer's disease. Glia 58, 831-838. doi: 10.1002/glia.20967 
Papadeas, S. T., Kraig, S. E., O’Banion, C., Lepore, A. C., and Maragakis, N. J. (2011). Astrocytes carrying the superoxide dismutase 1(SOD1 G93A) mutation induce wild type motor neuron degeneration in vivo. Proc. Natl. Acad. Sci. U.S.A. 108, 17803-17808. doi: 10.1073/pnas.1103141108

Pendlebury, W. W., Munoz-Garcia, D., and Perl, D. P. (1987). Cytoskeletal pathology in neurodegenerative diseases. Adv. Exp. Med. Biol. 221, 427-442. doi: 10.1002/ana.410420403

Prokop, P. S., Miller, K. R., and Heppner, S. L. (2013). Microglia actions In Alzheimer's disease. Acta Neuropathol. 126, 461-477. doi: 10.1007/s00401-0131182-x

Rajkowska, G., and Miguel-Hidalgo, J. J. (2007). Gliogenesis and glial pathology in depression. CNS Neurol. Disord. Drug Targets 6, 219-233. doi: $10.2174 / 187152707780619326$

Rama Rao, K. V., and Norenberg, M. D. (2014). Glutamine in the pathogenesis of hepatic encephalopathy: the trojan horse hypothesis revisited. Neurochem. Res. 39, 593-598. doi: 10.1007/s11064-012-0955-2

Rash, J. E., Kamasawa, N., Davidson, K. G., Yasumura, T., Pereda, A. E., and Nagy, J. I. (2012). Connexin composition in apposed gap junction hemiplaques revealed by matched double-replica freeze-fracture replica immunogold labeling. J. Membr. Biol. 245, 333-344. doi: 10.1007/s00232-012-9454-2

Reichenbach, A., Derouiche, A., and Kirchhoff, F. (2010). Morphology and dynamics of perisynaptic glia. Brain Res. Rev. 63, 11-25. doi: 10.1016/j.brainresrev.2010.02.003

Rönnbäck, L., and Hansson, E. (1992). Chronic encephalopathies induced by mercury or lead: aspects of underlying cellular and molecular mechanisms. $\mathrm{Br}$. J. Ind. Med. 49, 233-240. doi: 10.1136/oem.49.4.233

Rossi, D., Brambilla, L., Valori, C. F., Roncoroni, C., Crugnola, A., Yokota, T., et al. (2008). Focal degeneration of astrocytes in amyotrophic lateral sclerosis. Cell Death Differ. 15, 1691-1700. doi: 10.1038/cdd.2008.99

Rothhammer, V., and Quintana, F. J. (2015). Control of autoimmune CNS inflammation by astrocytes. Semin. Immunopathol. 37, 625-638. doi: 10.1007/s00281-015-0515-3

Shin, J. Y., Fang, Z. H., Yu, Z. X., Wang, C. E., Li, S. H., and Li, X. J. (2005). Expression of mutant huntingtin in glial cells contributes to neuronal excitotoxicity. J. Cell Biol. 171, 1001-1012. doi: 10.1083/jcb.200508072

Sica, R. E. (2012). Is amyotrophic lateral sclerosis a primary astrocytic disease? Med. Hypotheses 79, 819-822. doi: 10.1016/j.mehy.2012.08.036

Sica, R. E. (2015). Could astrocytes be the primary target of an offending agent causing the primary degenerative diseases of the human central nervous system? A hypothesis. Med. Hyphoteses 84, 481-489. doi: 10.1016/j.mehy.2015.02.004

Simpson, J. E., Ince, P. G., Lace, G., Forster, G., Shaw, P. J., Matthews, F., et al. (2010). MRC cognitive function and ageing neuropathology study group. Astrocyte phenotype in relation to Alzheimer-type pathology in the ageing brain. Neurobiol. Aging 31, 578-590. doi: 10.1016/j.neurobiolaging.2008. 05.015

Tong, J., Huang, C., Bi, F., Wu, Q., Huang, B., Liu, X., et al. (2013). Expression of ALS-linked TDP-43 mutant in astrocytes causes non-cell-autonomous motor neuron death in rats. EMBO J. 32, 1917-1926. doi: 10.1038/emboj.2013.122

Verkhratsky, A., Marutle, A., Rodríguez-Arellano, J. J., and Nordberg, A. (2014a). Glial asthenia and functional paralysis: a new perspective on neurodegeneration and Alzheimer's disease. Neuroscientist doi: 10.1177/1073858414547132 [Epub ahead of print].

Verkhratsky, A., Rodríguez, J. J., and Steardo, L. (2014b). Astrogliopathology: a central element of neuropsychiatric diseases? Neuroscientist 20, 576-588. doi: $10.1177 / 1073858413510208$

Verkhratsky, A., Olabarria, M., Noristani, H. N., Yeh, C. Y., and Rodriguez, J. J. (2010). Astrocytes in Alzheimer's disease. Neurotherapeutics 7, 399-412. doi: 10.1016/j.nurt.2010.05.017

Verkhratsky, A., and Parpura, V. (2015). Astrogliopathology in neurological, neurodevelopmental and psychiatric disorders. Neurobiol. Dis. 3, 1-8. doi: 10.1016/j.nbd.2015.03.025

Wharton, S. B., O'Callaghan, J. P., Savva, G. M., Nicoll, J. A., Matthews, F., Simpson, J. E., et al. (2009). MRC Cognitive Function and Ageing Neuropathology Study Group. Population variation in glial fibrillary acidic protein levels in brain ageing: relationship to Alzheimer-type pathology and dementia. Dement. Geriatr. Cogn. Disord. 27, 465-473. doi: 10.1159/000 217729

Yamanaka, K., Chun, S. J., Boillee, S., Fujimori-Tonou, N., Yamashita, H., Gutmann, D. H., et al. (2008). Astrocytes as determinants of disease progression in inherited amyotrophic lateral sclerosis. Nat. Neurosci. 11, 251-253. doi: $10.1038 / \mathrm{nn} 2047$

Yeh, C. Y., Vadhwana, B., Verkhratsky, A., and Rodriguez, J. J. (2011). Early astrocytic atrophy in the entorhinal cortex of a triple transgenic animal model of Alzheimer's disease. ASN Neuro 3, 271-279. doi: 10.1042/AN20110025

Conflict of Interest Statement: The authors declare that the research was conducted in the absence of any commercial or financial relationships that could be construed as a potential conflict of interest.

Copyright (c) 2016 Capani, Quarracino, Caccuri and Sica. This is an open-access article distributed under the terms of the Creative Commons Attribution License (CC BY). The use, distribution or reproduction in other forums is permitted, provided the original author(s) or licensor are credited and that the original publication in this journal is cited, in accordance with accepted academic practice. No use, distribution or reproduction is permitted which does not comply with these terms. 